\title{
Evaluation of Antifungal Activity of Nine Members of Family Euphorbiaceae of Lahore Region against Aspergillus niger, Rhizopus oryzae \& Alternaria solani
}

\author{
Kiran Zahid* \\ Department of Botany, Lahore College for Women University, Pakistan \\ *Corresponding author: Kiran Zahid, Department of Botany, Lahore College for Women University, Lahore, Pakistan. \\ To Cite This Article: Kiran Zahid, Evaluation of Antifungal Activity of Nine Members of Family Euphorbiaceae of Lahore Region against Aspergillus \\ niger, Rhizopus oryzae \& Alternaria solani. Am J Biomed Sci \& Res. 2019 - 6(3). AJBSR.MS.ID.001032. DOI: 10.34297/AJBSR.2019.06.001032.
}

Received: 眥 November 14, 2019; Published: 眥 November 22, 2019

\begin{abstract}
Present research was undertaken to analyze the antifungal potential of nine members of family Euphorbiaceae of Lahore region against three pathogenic fungi i.e. Aspergillus niger, Rhizopus oryzae \& Alternaria solani. Methanolic Leaf extracts were used for assessing the phytopathogenic activities of all the nine members of Family Euphorbiaceae via well diffusion method. All the plant extracts have showed significant results against two pathogenic fungi at all the four dose ranges $(32.12 \mu \mathrm{g} / \mathrm{ml}, 62.5 \mu \mathrm{g} / \mathrm{ml}, 125 \mu \mathrm{g} / \mathrm{ml}, 250 \mu \mathrm{g} / \mathrm{ml})$ used in the experiment while no results were observed against Alternaria solani. Maximum results were observed at $250 \mu \mathrm{g} / \mathrm{ml}$, zone of inhibition was found in the following order Euphorbia helioscopia $>$ Ricinus communis $>$ Phyllanthus emblica $>$ Croton tiglium $>$ Putranjiva roxburghii $>$ Euphorbia hirta $>$ Jatropha integerrima $>$ Euphorbia prostrata against Aspergillus niger. Among all the plants used only three species of Euphorbia i.e. E. prostrata, E. splendens and E. hirta have showed remarkable results against $R$. oryza. Hence conclude all the plant extracts have showed dose dependent activity which means maximum activity was observed at the concentration of $250 \mu \mathrm{g} / \mathrm{ml}$ at this concentration E. helioscopia possessed excellent activity against Aspergillus niger while maximum activity against Rhizopus oryzae at $250 \mu \mathrm{g} / \mathrm{ml}$ was observed by E. prostrata. Neither of the plants showed any response against Alternaria solani. This research leads to the discovery of plant extracts which could be a potential source in the treatment of multiple disorders associated with fungal strains such as Aspergillus niger and Rhizopus oryzae.
\end{abstract}

Keywords: Euphorbiaceae; Methanolic Extract; Aspergillus niger; Alternaria solani; Rhizopus oryzae

\section{Introduction}

Medicinal plants are the enrich source of secondary metabolites because they possess various pharmacological properties such as antimicrobial, antifungal, anticancer, antiviral and antioxidant properties [1]. Fungi are the main pathogens which have drastically affected the agricultural industries worldwide and leads to significant economic loss as mycotoxins produced by fungi have reduced nutritive value of crops making them unfit for human consumption [2]. Different strategies like synthetic chemicals, microwave or sonic drying and physical separation have been employed to minimize the loss of food and other agricultural commodities associated with fungal infections [3-5]. These protocols are found to be effective, but they don't meet the concerning safety and safeguarding requirements of the treated food [6].

Euphorbiaceae is one of the largest family of flowering plants consisted of 300 genera and 8,000 species. Plants from this family have been selected for current study because all the plants are the rich source of phytochemicals which allow their use for the treatment of multiple disorders such as cancer, diabetes, cardiovascular diseases, HCV as well as osteoarthritic ailments etc. Different plants like Acalypha indica L, Euphorbia hirta L, Euphorbia thymifolia L, Croton bonplandianumbaill, Jatropha gossypifolia L, Ricinus communis $\mathrm{L}$ have already been reported for the treatment of different ailments because all these plants are the rich source of secondary metabolites like alkaloids, flavonoids, steroids, saponin, phenolic compounds, fatty acid, esters, minerals, thereby they have been employed different activities in animals and human beings [7].

Different Phytochemical rich medicinal plants have been identified for the treatment of fungal infections. Methanolic extract from Lantana camara have showed significant antifungal activities against Aspergillus flavus and Aspergillus niger [8]. Similarly, aqueous and organic extracts of Tagetes minuta, Lippia 
javanica, Amaranthus spinosus and Vigna unguiculata have showed antifungal potential against four pathogenic fungi Fusarium verticillioides, F. proliferatum, Aspergillus flavus and A. parasiticus. Hence conclude all the four plant species act as a potential agrochemical fungicide in near future [9].

The aim of the current study was done in order to investigate the antifungal activity of nine members of Family Euphorbiaceae against three pathogenic fungal strains i.e. Aspergillus niger, Rhizopus oryzae and Alternaria solani using well diffusion method.

\section{Materials and Methods}

Nine plants were selected (Euphorbia prostrata, Euphorbia splendens, Euphorbia hirta, Euphorbia helioscopia, Jatropha integerrima, Ricinus communis, Putranjiva roxburghii and Croton tiglium) and collected from Lahore College for Women University, Lahore, Lawrence Garden and Harbanspura, Lahore. Plants were authenticated and deposited in Prem Madan Herbarium LCWU with respective Voucher specimens (E. hirta L. Voucher \# 0168, E. prostrata Ait. Voucher \# 0113, E. splendens Des Moul. Voucher \# 0171, Phyllanthus emblica Voucher \# 0393, Putranjiva roxburghii Wall. Voucher \# 0394, Ricinus communis Voucher \# 0402, Jatropha integerrima Jacq. Voucher 0395, Croton tiglium L. Voucher \# 0406, E. helioscopia L. 0176) for future use. The plant material was dried in shade, after drying the plant material was grinded to fine powder form, methanol extraction was carried in Soxhlet apparatus at $50^{\circ} \mathrm{C}$ and the methanol was evaporated under vacuum with the help of rotary evaporator and all the extract was stored at $4^{\circ} \mathrm{C}$.

The culture plates of Aspergilus niger, Rhizopus oryzae and Alternaria solani were obtained from Mycology and Pathology Department of Punjab University, Lahore. Pure culture of each fungal strain was obtained by culturing them on potato dextrose agar media. The media was prepared by dissolving 38g of PDA in $1000 \mathrm{ml}$ of distilled water, sterilized it under $121^{\circ} \mathrm{C}$ at $15 \mathrm{LBS}$ pressure for 15 minutes. The concentration of $250 \mu \mathrm{g} / \mathrm{ml}$ was utilized because it is considered as a nontoxic concentration and double dilutions was prepared from this stock which were utilized so as for the analysis of effect of plant extract against tested fungal strains. Discrete colonies from pure culture of each strain were picked and pre-cultured in $5 \mathrm{ml}$ sterile PDA broth, in well labelled test tubes, incubated in a rotary shaker overnight at $25^{\circ} \mathrm{C} .35 \mathrm{ml}$ sterile PDA media was poured in petri plates and allow them to solidify. Agar plates were inoculated with $100 \mu \mathrm{l} / 0.1 \mathrm{ml}$ broth culture of test fungal strains and spread over the surface of semisolid agar medium and shake it (Spread plate method) and kept for solidification. Wells were made with the help of a sterile cork and borer ( $3 \mathrm{~mm}$ in diameter) on the agar medium $\left({ }^{*}\right.$ well were made according to the size of petridishes $(9 \mathrm{~cm} / 11 \mathrm{inch})$ ) Wells were filled with the $40 \mu \mathrm{l}$ of different concentration of plant extract while central well was filled with methanol which was kept as control so as to nullify the effect of methanol in the plant extract. The plates were then incubated at $37^{\circ} \mathrm{C}$ for 4-7 days depend upon the fungal strain. After incubation zone of inhibition were measured in millimeters. Antifungal standard drugs (Ketoconazole, Econazole, Nystatin, Amphotericin, Clotrimazole and Miconazole) were used as positive control. Three replicates for each extract against each of the test fungal strains were taken.

\section{Minimum Inhibitory Concentration (MIC)}

MIC of all the plant extracts was determined against each of the test microorganisms in triplicate. Two-fold double dilutions of plant extracts from $250 \mu \mathrm{g} / \mathrm{ml}$ to $31.2 \mu \mathrm{g} / \mathrm{ml}$ were used to determine MIC. The MIC was considered as the lowest concentration of the extract in agar plate showing no visible fungal growth after 4-7days incubation at $37^{\circ} \mathrm{C}$.

\section{Statistical Application}

Calculate the significance of the result by measuring Mean and Standard deviation. Mean and standard deviation (SD) of the data was determined with the help of SPSS software.

\section{Results and Discussion}

\section{Antifungal Activity}

The disc diffusion method for antifungal activity showed significant reduction in fungal growth in terms of zone of inhibition around the disc. Among fungal forms tested, Aspergillus niger, Rhizopus oryzae were found to be more sensitive to crude extract. The methanolic extract of Euphorbia hirta, Euphorbia prostrata, Euphorbia helioscopia, Euphorbia splendens, Ricinus communis, Putranjiva roxburghii, Phyllanthus emblica, Croton tiglium, Jatropha integerrima were proved to be effective against Aspergillus niger \& Rhizopus oryzae while they do not show any effect towards Alternaria solani. The result showed that E. helioscopia exhibited dose-dependent activity against Aspergillus niger while maximum activity against Rhizopus oryzae at $250 \mu \mathrm{g} / \mathrm{ml}$ was observed by E. prostrata. However, none of the plant extract showed any activity against Alternaria solani (Table 1).

Antifungal activity of E. prostrata, E. splendens, E. hirta, E. helioscopia, R. communis, J. integerrima, P. roxburghii, P. emblica, C. tiglium were studied against three different fungal strains i.e. $A$. niger, R. oryza, A. solani. Methanolic extracts of all plants with four concentrations $(31.2,62.5,125,250 \mu \mathrm{g} / \mathrm{ml})$ were used against each of three fungal strains. Methanol was proved to be excellent solvent in extracting phytochemicals and inhibitory substances from plant materials $[10,11]$. The zones of inhibition were measured, and MIC was evaluated in this study (Figure $1 \& 2$ ).

The methanolic extract of E. helioscopia exhibited good activity against all tested fungal strains. It showed maximum zone of inhibition against $A$. niger at $125 \& 250 \mu \mathrm{g} / \mathrm{ml}$ while moderate zone of inhibition at $31.25 \& 62.5 \mu \mathrm{g} / \mathrm{ml}$ against $A$. niger \& R. oryza. The methanolic extract of E. prostrata showed highest antifungal activity against $R$. oryza (18 and $15 \mathrm{~mm}$ respectively), while it showed moderate activity against $A$. niger $(9 \mathrm{~mm}$ and $7 \mathrm{~mm}$ ) and no activity 
against $A$. solani. An excellent activity showed by methanolic extract of E. splendens against $R$. oryza (16- and 14-mm zone of inhibition) as compared to A. niger and A. solani. The concentration of 250 $\mu \mathrm{g} / \mathrm{ml}$ of $E$. hirta inhibited the maximum growth of $R$. oryza ( 9 and $12 \mathrm{~mm}$ ), it showed moderate activity against $A$. niger while no response was observed against $A$. solani. The maximum inhibition of the growth of $A$. niger $(13 \mathrm{~mm})$ take place by methanolic extract of R. communis and methanolic extract of R. communis causes the minimum inhibition of the $R$. oryza and show not even a little effect towards $A$. solani. The methanolic extract of $J$. integerrima possesses antifungal activity against $A$. niger as well as $R$. oryza and poor activity against $A$. solani. The growth $(4-11 \mathrm{~mm})$ of all tested fungal strains except $A$. solani was suppressed by the methanolic extract of $P$. roxburghii. An excellent antifungal activity showed by methanolic extract of $P$. emblica against all tested fungal strains except $A$. solani by increased in the concentration of the plant extract. The methanolic extract showed maximum activity at 125 and $250 \mu \mathrm{g} / \mathrm{ml}$ against $A$. niger and $R$. oryza while no activity was observed against $A$. solani.

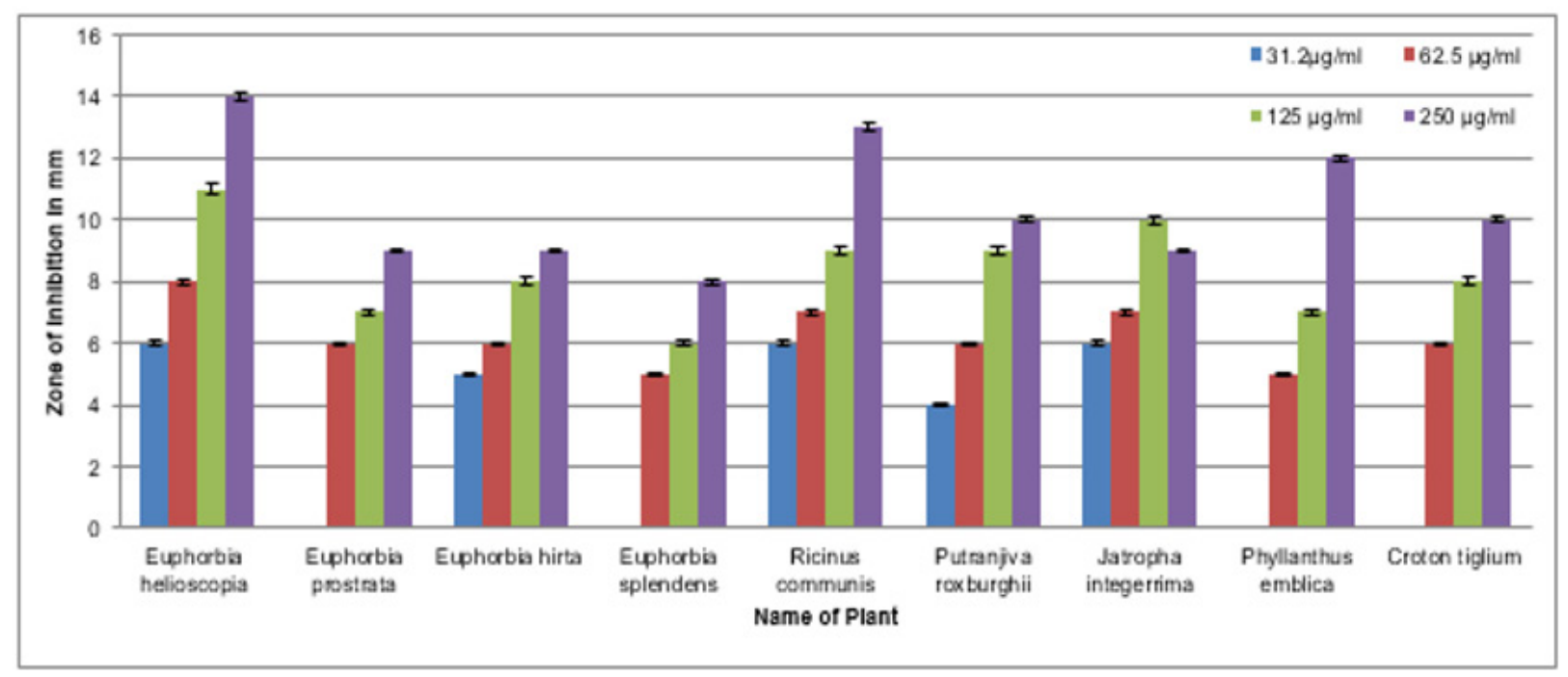

Figure 1: Zone of inhibition of different plant extracts in $\mathrm{mm}$ against Aspergillus niger.

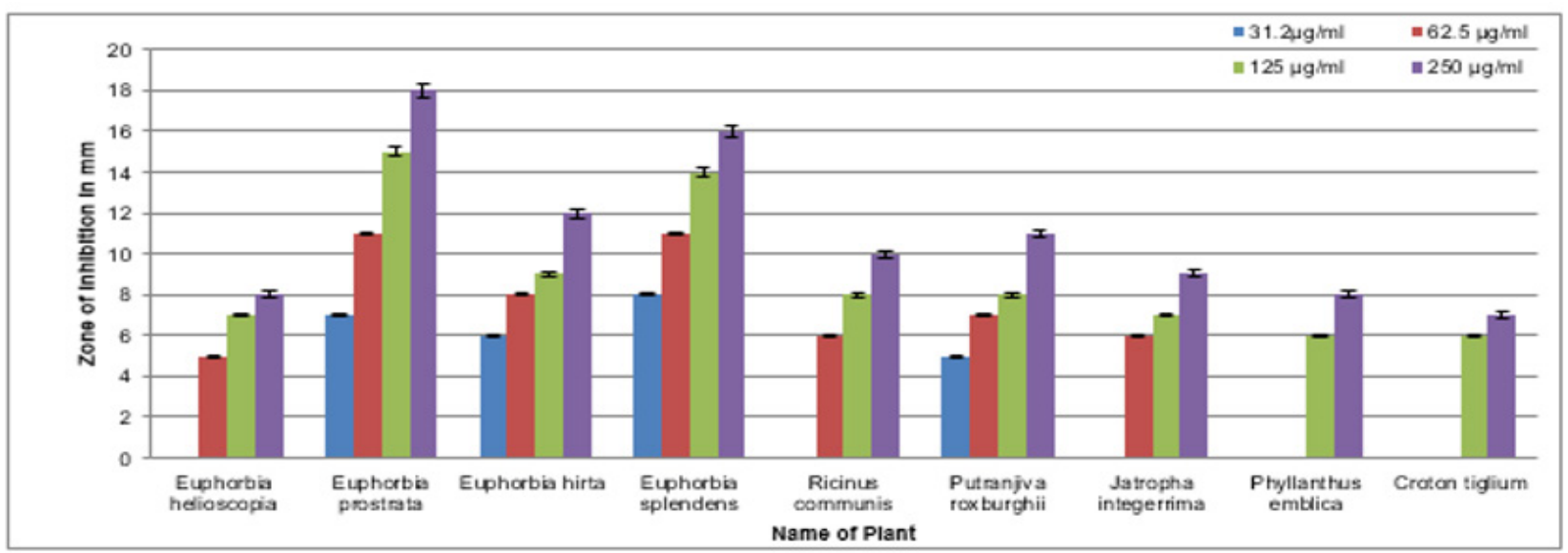

Figure 2: Zone of inhibition of different plant extracts in $\mathrm{mm}$ against Rhizopus oryzae.

Table 1: Statistical Analysis of Antifungal activity by nine members of Family Euphorbiaceae.

\begin{tabular}{|c|c|c|c|}
\hline \multirow{2}{*}{ Application } & Zone of inhibition (mm) & Conc of Plant Extract (250 $\boldsymbol{\mu g} / \mathbf{m l})$ & Remarks \\
\hline \multirow{2}{*}{ E. helioscopia } & Aspergillus niger & $14.10 \pm 0.66$ & Significant \\
\cline { 2 - 4 } & Rhizopus oryzae & $8.17 \pm 0.29$ & Moderate \\
\hline \multirow{2}{*}{ E. prostrata } & Aspergillus niger & $9.50 \pm 0.50$ & Moderate \\
\cline { 2 - 4 } & Rhizopus oryzae & $18.29 \pm 0.26$ & Significant \\
\hline \multirow{2}{*}{ E. hirta } & Aspergillus niger & $9.40 \pm 0.36$ & Significant \\
\cline { 2 - 4 } & Rhizopus oryzae & $12.23 \pm 0.28$ & Significant \\
\hline
\end{tabular}




\begin{tabular}{|c|c|c|c|}
\hline \multirow{2}{*}{ E. splendens } & Aspergillus niger & $8.50 \pm 0.50$ & Significant \\
\hline & Rhizopus oryzae & $16.47 \pm 0.34$ & Significant \\
\hline \multirow{2}{*}{ R. communis } & Aspergillus niger & $13.40 \pm 0.36$ & Significant \\
\hline & Rhizopus oryzae & $10.39 \pm 0.28$ & Significant \\
\hline \multirow{2}{*}{ P. roxburghii } & Aspergillus niger & $10.40 \pm 0.36$ & Significant \\
\hline & Rhizopus oryzae & $11.40 \pm 0.36$ & Significant \\
\hline \multirow{2}{*}{ J. integerrima } & Aspergillus niger & $9.50 \pm 0.50$ & Significant \\
\hline & Rhizopus oryzae & $9.30 \pm 0.40$ & Significant \\
\hline \multirow{2}{*}{ P. emblica } & Aspergillus niger & $12.33 \pm 0.29$ & Significant \\
\hline & Rhizopus oryzae & $8.17 \pm 0.29$ & Moderate \\
\hline \multirow{2}{*}{ C. tiglium } & Aspergillus niger & $10.83 \pm 0.29$ & Significant \\
\hline & Rhizopus oryzae & $7.32 \pm 0.18$ & Mild \\
\hline \multirow{3}{*}{ Ketoconazole } & Aspergillus niger & $12.21 \pm 0.25$ & Significant \\
\hline & Rhizopus oryzae & $14.39 \pm 0.43$ & Significant \\
\hline & Alternaria solani & $20.17 \pm 0.26$ & Significant \\
\hline \multirow{3}{*}{ Econazole } & Aspergillus niger & $14.19 \pm 0.23$ & Significant \\
\hline & Rhizopus oryzae & $19.17 \pm 0.21$ & Significant \\
\hline & Alternaria solani & $21.52 \pm 0.19$ & Significant \\
\hline \multirow{3}{*}{ Nystatin } & Aspergillus niger & $22.21 \pm 0.25$ & Significant \\
\hline & Rhizopus oryzae & $16.41 \pm 0.39$ & Significant \\
\hline & Alternaria solani & $22.17 \pm 0.26$ & Significant \\
\hline \multirow{3}{*}{ Amphotericin } & Aspergillus niger & $16.39 \pm 0.32$ & Significant \\
\hline & Rhizopus oryzae & $17.14 \pm 0.28$ & Significant \\
\hline & Alternaria solani & $23.25 \pm 0.29$ & Significant \\
\hline \multirow{3}{*}{ Clotrimazole } & Aspergillus niger & $18.39 \pm 0.32$ & Significant \\
\hline & Rhizopus oryzae & $17.25 \pm 0.29$ & Significant \\
\hline & Alternaria solani & $18.39 \pm 0.34$ & Significant \\
\hline \multirow{3}{*}{ Miconazole } & Aspergillus niger & $18.39 \pm 0.43$ & Significant \\
\hline & Rhizopus oryzae & $14.19 \pm 0.23$ & Significant \\
\hline & Alternaria solani & $20.33 \pm 0.24$ & Significant \\
\hline
\end{tabular}

All plant extracts have showed significant results against Aspergillus niger, Rhizopus oryzae while non-significant results against Alternaria solani Mild $>8$, Moderate $<8$, Significant $<12$

The results of the present investigation clearly indicate that all the plants (E. prostrata, E. splendens, E. hirta, E. helioscopia, R. communis, J. integerrima, P. roxburghii, P. emblica and C. tiglium) showed significant antifungal activity against two fungal strains $(A$. niger \& R. oryza) as compared with different commercially available antibiotics like Ketoconazole, Econazole, Nystatin, Amphotericin, Clotrimazole and Miconazole (Table 1). The inhibitory effect of the above plants against pathogenic fungal strains can introduce these plants as a potential product for the development of drug for the treatment of different diseases caused by these pathogenic bacteria.

\section{References}

1. Nabavi SF, Lorenzo AD, Izadi M, Sobarzo-Sánchez E, Daglia M, et al. (2015) Antibacterial Effects of Cinnamon: From Farm to Food, Cosmetic and Pharmaceutical Industries. J Nutrients 7(9): 7729-7748.

2. Mahlo SM, Eloff JN (2014) Acetone leaf extracts of Breonadia salicina (Rubiaceae) and ursolic acid protects oranges against infection by Penicillium species. S Afri J Bot 93: 48-53.

3. Huwig A, Freimund S, Kappeli O, Dutler H (2001) Mycotoxin detoxication of animal feed by different adsorbents. Toxicol Lett 122(2): 179-188.
4. Katerere DR, Shephard GS, Faber M (2008) Infant malnutrition and chronic aflatoxicosis in Southern Africa: is there a link. Int J Food Safety, Nutrition and Public Health 1: 2.

5. Bankole SA (2006) Mycotoxins in food systems in Sub-Saharan Africa: a review. Mycotoxin Research 22(3): 163-169.

6. Piva GFP, Galvano FRD, Pietri AAP, Piva ARD (1995) Detoxification methods of aflatoxins. A review. Nutrition Research 15(5): 767-776.

7. Islam Md S, Ara H, Ahkad K, Uddin Md M (2019) A review on medicinal uses of different plants of Euphorbiaceae family. Universal J Pharm Res 4: 47-51.

8. Fayaz, M, Bhat MH, Fayaz M, Kumar A, Jain AK (2017) Antifungal activity of Lantana camara L. leaf extracts in different solvents against some pathogenic fungal strains. Pharmacologia 8(3): 105-112.

9. Thembo KM, Vismer HF, Nyazema NZ, Gelderblom WCA, Katerere DR (2010) Antifungal activity of four weedy plant extracts against selected mycotoxigenic fungi. J Appl Microbiol 109(4): 1479-1486.

10. Eloff JN (1998) Which extract should be used for the screening and isolation of antimicrobial components from plants. J Ethnopharmacol 60(1): 1-8.

11. Cowan MM (1999) Plant products as antimicrobial agents. Clin Microbio 12(4): 564-582. 
12.Sailaja I (2014) Antifungal activity of some wild plant extracts against fungal pathogens. Int J Integrat Med Sci 1: 41-44.

13.Sathish R, Vyawahare B, Natarajan K (2011) Antiulcerogenic activity of Lantana camara leaves on gastric and duodenal ulcers in experimental rats. J Ethnopharmacol 134(1): 195-197.

14.Satish S, Mohana DC, Ranhavendra MP, Raveesha KA (2007) Antifungal activity of some plant extracts against important seed borne pathogens of Aspergillus sp. J Agric Technol 3: 109-119.
15.Sharma OP, Sharma S, Pattabhi V, Mahato SB, Sharma PD (2007) A review of the hepatotoxic plant Lantana camara. Crit Rev Toxicol $37(4): 313-352$.

16. Ashraf Z, Muhammad A, Imran M, Tareq AH (2011) In vitro antibacterial and antifungal activity of methanol, chloroform and aqueous extracts of Origanum vulgare and their comparative analysis. Int J Org Chem 1: 257-261. 